\title{
Technical note: A rapid enzyme-linked immunosorbent assay blood test for pregnancy in dairy and beef cattle
}

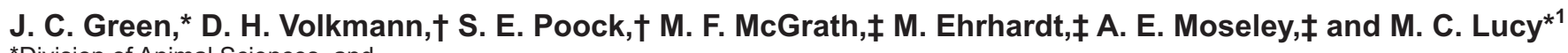 \\ *Division of Animal Sciences, and \\ †College of Veterinary Medicine, University of Missouri, Columbia 65211 \\ ‡Monsanto Co., St. Louis, MO 63198
}

\section{ABSTRACT}

The ruminant trophoblast produces pregnancyassociated glycoproteins (PAG) that can be detected in the blood of pregnant animals. The objective was to determine the accuracy of a rapid ELISA PAGbased test for the purpose of pregnancy detection in cattle. Blood was sampled from dairy cattle $(539 \mathrm{Hol}-$ stein cows, 173 Holstein heifers, 73 Guernsey cows, 22 Guernsey heifers, and 12 Jersey heifers) and crossbred beef cattle ( 145 cows and 46 heifers) that were $\geq 25 \mathrm{~d}$ after insemination (range $=25$ to $45 \mathrm{~d}$ for dairy and 29 to $56 \mathrm{~d}$ for beef). Cattle were examined by ultrasonography for detection of pregnancy within $2 \mathrm{~d}$ of blood collection. Whole blood or plasma was incubated in a polystyrene tube coated with a monoclonal PAG antibody for $15 \mathrm{~min}$. The tubes were then washed and subjected to sequential incubations with a biotinylated polyclonal PAG antibody (15 min, followed by wash), a horseradish peroxidase-streptavidin solution (15 min, followed by wash), and a peroxidase substrate. Tubes were visually assessed for color after $15 \mathrm{~min}$ (clear solution $=$ PAG negative, not pregnant; blue solution = PAG positive, pregnant). Total assay time was approximately $90 \mathrm{~min}$. The ultrasound examination was used as the standard for pregnancy diagnosis. The sensitivity $(99.8 \pm 0.2 \%)$, specificity $(91.7 \pm 1.4 \%)$, and negative predictive value $(99.7 \pm 0.3 \%)$ for the PAG test used in dairy cattle were similar for different breeds and for cows and heifers. The positive predictive value for the test was greater in dairy heifers than in dairy cows $(96.5 \pm 1.4 \%$ vs. $90.5 \pm 1.7 \%$, respectively). In beef cattle, the sensitivity $(100 \%)$, specificity $(92.3 \pm 3.0 \%)$, positive predictive value $(95.0 \pm 2.0 \%)$, and negative predictive value $(100 \%)$ for the PAG test were similar for cows and heifers. The accuracy of the test was not different for dairy and beef cattle. In conclusion, the rapid ELISA pregnancy test based on PAG was highly

Received February 11, 2009.

Accepted April 2, 2009.

${ }^{1}$ Corresponding author: LucyM@missouri.edu sensitive and specific for pregnancy detection in dairy and beef cattle.

Key words: pregnancy test, pregnancy-associated glycoproteins (PAG), blood, rapid

Cattle that are not observed in estrus after insemination are scheduled for a pregnancy diagnosis within 35 to $60 \mathrm{~d}$. The examination is typically performed by manual palpation of the uterus and its contents (Romano et al., 2007). Using ultrasonography can shorten the time interval from insemination to pregnancy diagnosis to between 25 and $35 \mathrm{~d}$ after insemination (Fricke, 2002). In either case, transrectal palpation and ultrasonography of the uterus require a skilled operator (typically a veterinarian) and represent a major component of routine reproductive management on dairy farms.

Blood tests for pregnancy in cattle were first described in the 1980s (Sasser et al., 1986). The original tests were based on pregnancy-specific protein B (PSPB), a pregnancy-associated glycoprotein (PAG) found in the blood of pregnant cattle (Sasser and Ruder, 1987). The PSPB test is commercially available by the trade name BioPRYN (BioTracking LLC, Moscow, ID). A blood sample is collected and transported to a commercial laboratory and results are generally returned in 2 to 3 d. Cows tested for PSPB must be at least $90 \mathrm{~d}$ postpartum because PSPB from the preceding pregnancy can manifest as a false-positive result in nonpregnant cows. Service providers for this test state that cows must be at least $30 \mathrm{~d}$ postinsemination when the test is conducted.

The use of a blood test for pregnancy diagnosis in dairy cattle represents a major advance in reproductive management, because it obviates the need for specialized skills or ultrasound equipment. The objective was to evaluate the use of a PAG-based, rapid ELISA pregnancy test for cattle that can be used as early as $25 \mathrm{~d}$ postinsemination. The test is based on antibodies raised against a subset of PAG that are expressed early during pregnancy and cleared rapidly from the blood of postpartum cows (Green et al., 2005). Performing 
the test requires approximately $90 \mathrm{~min}$. Neither sophisticated laboratory equipment nor high degrees of technical skill are needed for its completion. This rapid ELISA test would provide a convenient option or addition to traditional means of pregnancy detection.

Lactating dairy cows ( $\mathrm{n}=539$ Holstein and 73 Guernsey) and heifers ( $\mathrm{n}=173$ Holstein, 22 Guernsey, and 12 Jersey) were housed at the University of Missouri Foremost Dairy Farm. Data were collected from February 2007 to January 2009. Cows were milked twice daily, housed in a free-stall barn with a grooved concrete floor, and fed a TMR consisting of corn silage, alfalfa haylage, grass hay, concentrates, and a vitamin and mineral mixture. The rolling herd average (305-d mature-equivalent milk production) for the farm exceeded 10,000 kg. Heifers were housed in a shed with free-stalls and fed free-choice grass hay and orts from the lactating cow pens. Dairy cattle were bred by AI. Blood was collected for pregnancy diagnosis regardless of the stage of lactation (DIM at blood collection: median $=167$; range $=67$ to $771 \mathrm{~d}$ ). Most cows were enrolled in an estrus-synchronization program for their first insemination (Presynch Ovsynch; Moreira et al., 2001). Subsequent inseminations were performed approximately $12 \mathrm{~h}$ after observed return to estrus, or by using a rapid resynchronization program [cow with a corpus luteum and not pregnant at pregnancy examination; $\mathrm{PGF}_{2 \alpha}$ (25 mg of Lutalyse i.m., Pfizer Inc., New York, NY) followed $48 \mathrm{~h}$ later by GnRH (100 $\mu \mathrm{g}$ of Factrel i.m., Fort Dodge Animal Health, Fort Dodge, IA), followed $16 \mathrm{~h}$ later by $\mathrm{AI}$ ], or by using a progesterone insert containing $1.38 \mathrm{~g}$ of progesterone (Eazi-Breed CIDR, Pfizer Animal Health) within the Ovsynch program (El-Zarkouny et al., 2004; cow without a corpus luteum and not pregnant at pregnancy examination). Heifers (median age $=491 \mathrm{~d}$ ) were inseminated after an observed estrus or synchronized estrus induced by $\mathrm{PGF}_{2 \alpha}$. Pregnancy diagnoses were performed by 1 of 3 theriogenologists from the University of Missouri College of Veterinary Medicine using transrectal ultrasonography (Aloka SSD-500 with a 5-MHz transducer; Aloka Co., Tokyo, Japan). Animals were only diagnosed pregnant when an embryo was demonstrated inside a fluid-filled uterine horn. Blood for the PAG test was collected from the median caudal vein or artery into tubes containing $100 \mu \mathrm{L}$ of a $15 \%$ solution of EDTA $\left(\mathrm{K}_{3}\right)$ (Tyco Healthcare Group, Mansfield, MA). In general, blood was collected and tested for PAG $1 \mathrm{~d}$ before ultrasonographic pregnancy diagnosis.

Beef cattle were housed on fescue pasture at the University of Missouri South Farm $(\mathrm{n}=80$ cows and 26 heifers $)$ or at a private farm $(\mathrm{n}=65$ cows and 20 heifers). Cows calved in spring 2008 and were nursing calves at the time of breeding and pregnancy detection
(DIM at blood collection: median $=112 ;$ range $=50$ to 297 d). Cattle were exposed to bulls approximately 14 d after first AI. Ultrasonographic pregnancy diagnoses were performed by a theriogenologist from the University of Missouri College of Veterinary Medicine (private farm) or by 1 of 3 trained graduate students from the University of Missouri Division of Animal Sciences (South Farm). Equipment used for ultrasonography was an Aloka SSD-500 equipped with a $5-\mathrm{MHz}$ transducer (private farm) or an Aloka SSD-900 equipped with a 7.5-MHz transducer (South Farm). Blood was collected at the time of ultrasonographic pregnancy examination using the procedures described for dairy animals.

The pregnancy test was conducted by using either whole blood or plasma (collected after centrifugation at $1,500 \times g$ for $10 \mathrm{~min})$. In some instances, plasma was stored at $-20^{\circ} \mathrm{C}$ and thawed in warm water immediately before the assay. The procedure for the test was the same for whole blood and plasma. Two antibodies were used in the assay (a "sandwich" style ELISA). The capture antibody was a PAG monoclonal antibody raised against proteins isolated from bovine placental cotyledons (Green et al., 2005). The PAG monoclonal antibody was diluted in sodium carbonate buffer and used to coat polystyrene tubes $(12 \times 75 \mathrm{~mm}$ polystyrene tubes, Evergreen Scientific, Los Angeles, CA) for $18 \mathrm{~h}$ at $6^{\circ} \mathrm{C}$. The detection antibody was a polyclonal PAG antibody raised against PAG protein purified from d 55 bovine placentas. The polyclonal antibody was biotinlabeled using the Biotin Protein Labeling Kit (Roche Applied Science, Indianapolis, IN) and diluted in PBSTween (PBS-T; $137 \mathrm{mM} \mathrm{NaCl}, 2.7 \mathrm{mM} \mathrm{KCl}, 10 \mathrm{mM}$ $\mathrm{Na}_{2} \mathrm{HPO}_{4}, 1.8 \mathrm{mM} \mathrm{KH}_{2} \mathrm{PO}_{4}$, and $0.5 \%$ Tween-20) to approximately $1.3 \mu \mathrm{g} / \mathrm{mL}$.

Whole blood or plasma $(400 \mu \mathrm{L})$ was pipetted into the antibody-coated tube, placed into a foam rack, and incubated for $15 \mathrm{~min}$ in a water bath at $37^{\circ} \mathrm{C}$. After the incubation, the tubes were decanted and washed 3 times (filled and inverted) with PBS-T solution. The biotin-labeled polyclonal PAG antibody was then added to the tubes and the tubes were allowed to incubate in a water bath for $15 \mathrm{~min}$ at $37^{\circ} \mathrm{C}$. Tubes were then decanted and washed twice with PBS-T solution. Streptavidin-horseradish peroxidase (Pierce Thermo Scientific, Rockford, IL), diluted to $20 \mathrm{ng} / \mathrm{mL}$ with PBS-T solution, was added to the tubes and the tubes were allowed to incubate in a water bath for $15 \mathrm{~min}$ at $37^{\circ} \mathrm{C}$. Tubes were decanted and washed twice with PBS-T. A peroxidase substrate solution (KPL Inc., Gaithersburg, MD) was added and allowed to incubate for $15 \mathrm{~min}$ at room temperature. The solution in the tubes was then visually and subjectively assessed for color (blue color = PAG present, pregnant diagnosis; clear $=$ no PAG present, nonpregnant diagnosis; Figure 


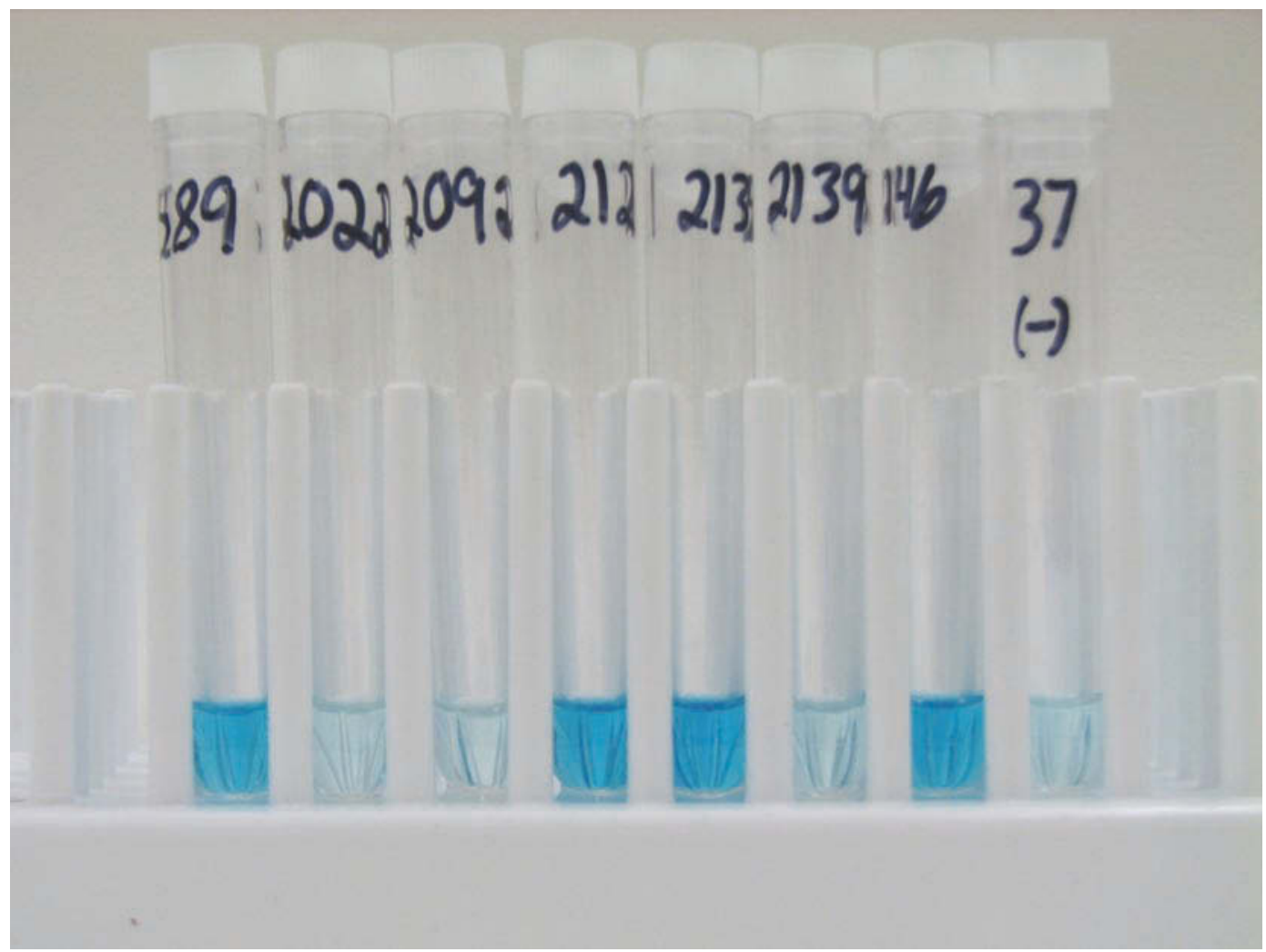

Figure 1. Photograph of completed pregnancy tests for 8 cows. From the left, the second (cow 2022), third (cow 2092), sixth (cow 2139), and eighth (cow 37; negative control) tube did not have a blue color and the diagnosis was nonpregnant. The other tubes had a blue color and cows were diagnosed pregnant.

1). The accuracy of visual interpretation of the test was $98.3 \%$ when 30 samples from 9 pregnant cows $[25 \mathrm{~d}$ postinsemination $(\mathrm{n}=5) ; 26 \mathrm{~d}$ or greater postinsemination $(\mathrm{n}=4)$ ] and 21 nonpregnant cows were visually assessed by 8 people who were novices for reading the test.

The sensitivity [(number of cattle correctly diagnosed with a positive blood pregnancy test/the number of cattle with a positive ultrasonographic pregnancy test) $\times 100]$; specificity [(number of cattle correctly diagnosed with a negative blood pregnancy test/number of cattle with negative ultrasonographic pregnancy test) $\times 100]$; positive predictive value $[\mathbf{P P V}$, (number of cattle correctly diagnosed with a positive blood and positive ultrasonographic pregnancy test / total number of cattle with a positive blood pregnancy test $) \times 100]$; negative predictive value $[\mathbf{N P V}$, (number of cattle correctly diagnosed with a negative blood pregnancy test and a negative ultrasonographic pregnancy test/ total number of cattle with negative blood pregnancy test) $\times 100]$; and accuracy [ACY, (number of correct blood pregnancy tests/total number of blood pregnancy tests $) \times 100$ ] were calculated for the blood pregnancy test. Differences between groups (cows vs. heifers, beef vs. dairy) for sensitivity, specificity, PPV, NPV, and ACY were tested for significance by using a Fisher's Exact Test. The data are reported as the proportion \pm standard error, where $\mathrm{SE}=\sqrt{ }(p q / \mathrm{n})$ (Snedecor and Cochran, 1989).

A total of 1,010 samples were analyzed (612 dairy cows, 207 dairy heifers, 145 beef cows, and 46 beef heifers). Of these, 529 cattle were diagnosed pregnant by ultrasonography and 481 cattle were diagnosed nonpregnant by ultrasonography (Table 1). One pregnant cow tested nonpregnant by the blood test (false-negative result) and 39 nonpregnant cattle tested pregnant by the blood test (false-positive result). Based on the data in Table 1, the sensitivity, specificity, PPV, NPV, and ACY for dairy cows, dairy heifers, beef cows, and beef heifers were calculated (Table 2).

When all cattle were considered, the sensitivity and NPV of the test approached $100 \%$ and were nearly identical for the respective groups (cows and heifers, dairy and beef cattle; $P>0.10$ ). The specificity and PPV were $91.9 \pm 1.2 \%$ and $93.1 \pm 1.1 \%$ for all cattle. The specificity ranged from $86.4 \pm 5.2 \%$ for dairy heifers to $94.4 \pm 5.4 \%$ for beef heifers and was not different between the respective groups $(P>0.10)$. The PPV 
Table 1. Contingency tables used to determine the sensitivity, specificity, positive predictive value, negative predictive value, and accuracy of the rapid ELISA pregnancy test for dairy cows, dairy heifers, beef cows, and beef heifers

\begin{tabular}{lcrl}
\hline & \multicolumn{2}{c}{ Transrectal ultrasonography } & \\
\cline { 2 - 2 } Group & Embryo present & Embryo absent & Total \\
\hline Dairy cows & & & \\
Blood pregnancy test positive & 256 & 27 & 283 \\
Blood pregnancy test negative & 1 & 328 & 329 \\
Total & 257 & 355 & 612 \\
Dairy heifers & 163 & 6 & 169 \\
Blood pregnancy test positive & 0 & 38 & 38 \\
Blood pregnancy test negative & 163 & 44 & 207 \\
Total & & & 90 \\
Beef cows & 85 & 55 & 145 \\
Blood pregnancy test positive & 0 & 60 & 29 \\
Blood pregnancy test negative & 85 & 1 & 17 \\
Total & 28 & 17 & 46 \\
Beef heifers & 0 & 18 & 567 \\
Blood pregnancy test positive & 28 & 443 \\
Blood pregnancy test negative & & & \\
Total & 528 & 39 & 1,010 \\
Total & 1 & 442 & \\
Blood pregnancy test positive & 529 & 481 & \\
Blood pregnancy test negative & & & \\
Total & & & \\
\hline
\end{tabular}

ranged from $90.5 \pm 1.7 \%$ for dairy cows to $96.6 \pm 3.4 \%$ for beef heifers. Dairy cows had a lesser $(P<0.05)$ PPV than dairy heifers. The overall ACY was $96 \%$ and similar $(P>0.10)$ for the respective groups. The sensitivity, specificity, PPV, NPV, and ACY of the PAG test were similar for the different dairy breeds (data not shown).

There were 147 samples collected between 25 and $29 \mathrm{~d}$ after insemination, 718 samples collected between 30 and $34 \mathrm{~d}$ after insemination, and 130 samples collected at 35 or more days after insemination (Table 3 ). Regardless of the day of collection, the sensitivity and
NPV of the test approached $100 \%$ (Table 4). The specificity, PPV, and ACY of the test were generally greater than $95 \%$ for samples collected on d 25 to 29 and for samples collected on d 30 to 34. Specificity, PPV, and ACY were lower $(P<0.05)$ for cattle sampled $\geq \mathrm{d} 35$ after AI.

The use of a test for pregnancy-specific proteins for pregnancy diagnosis was first described by Sasser et al. (1986). Since that report, major advances in ELISAbased pregnancy tests have evolved (Gábor et al., 2007). For example, Friedrich and Holtz (2009) described a pregnancy test based on bovine PAG-1. The accuracy

Table 2. Sensitivity, specificity, positive predictive value (PPV), negative predictive value (NPV), and accuracy (ACY) ( \pm SE) for the rapid ELISA pregnancy test when used for dairy cows, dairy heifers, beef cows, and beef heifers ${ }^{1}$

\begin{tabular}{|c|c|c|c|c|c|}
\hline Type & Sensitivity, \% (n/n) & Specificity, \% (n/n) & $\mathrm{PPV}, \%(\mathrm{n} / \mathrm{n})$ & $\mathrm{NPV}, \%(\mathrm{n} / \mathrm{n})$ & $\mathrm{ACY}, \%(\mathrm{n} / \mathrm{n})$ \\
\hline $\begin{array}{l}\text { Dairy heifer } \\
(\mathrm{n}=207)\end{array}$ & 100 & $\begin{array}{c}86.4 \pm 5.2 \\
(38 / 44)\end{array}$ & $\begin{array}{c}96.5 \pm 1.4^{\mathrm{b}} \\
(163 / 169)\end{array}$ & 100 & $\begin{array}{c}97.1 \pm 1.2 \\
(201 / 207)\end{array}$ \\
\hline $\begin{array}{l}\text { Beef cow } \\
(\mathrm{n}=145)\end{array}$ & $100(85 / 85)$ & $\begin{array}{c}91.7 \pm 3.6 \\
(55 / 60)\end{array}$ & $\begin{array}{c}94.4 \pm 2.4^{\mathrm{ab}} \\
(85 / 90)\end{array}$ & 100 & $\begin{array}{c}96.6 \pm 1.5 \\
(140 / 145)\end{array}$ \\
\hline $\begin{array}{l}\text { Beef heifer } \\
(\mathrm{n}=46)\end{array}$ & 100 & $\begin{array}{c}94.4 \pm 5.4 \\
(17 / 18)\end{array}$ & $\begin{array}{c}96.6 \pm 3.4^{\mathrm{ab}} \\
(28 / 29)\end{array}$ & 100 & $\begin{array}{c}97.8 \pm 2.2 \\
(45 / 46)\end{array}$ \\
\hline
\end{tabular}

\footnotetext{
${ }^{\mathrm{a}, \mathrm{b}}$ Mean percentages having different superscript letters differ $(P<0.05)$.

${ }^{1}$ Sensitivity $=$ (number of cattle correctly diagnosed with a positive blood pregnancy test/the number of cattle with positive ultrasonographic pregnancy test $) \times 100$; specificity $=$ (number of cattle correctly diagnosed with a negative blood pregnancy test/number of cattle with a negative ultrasonographic pregnancy test $) \times 100 ; \mathrm{PPV}=$ (number of cattle correctly diagnosed with a positive blood pregnancy test and a positive ultrasonographic pregnancy test/total number of cattle with a positive blood pregnancy test) $\times 100 ; \mathrm{NPV}=$ (number of cattle correctly diagnosed with a negative blood pregnancy test and a negative ultrasonographic pregnancy test/total number of cattle with a negative blood pregnancy test $) \times 100$; and accuracy $=($ number of correct blood pregnancy tests/total number of blood pregnancy tests $) \times 100$.
} 
Table 3. Contingency tables used to determine the sensitivity, specificity, positive predictive value, negative predictive value, and accuracy of the rapid ELISA pregnancy test for dairy cows, dairy heifers, beef cows, and beef heifers on different days after insemination

\begin{tabular}{lccr}
\hline & \multicolumn{2}{c}{ Transrectal ultrasonography } & \\
\cline { 2 - 3 } Item & Embryo present & Embryo absent & Total \\
\hline Days 25 to 29 after insemination & & & \\
Blood pregnancy test positive & 87 & 5 & 92 \\
Blood pregnancy test negative & 1 & 54 & 55 \\
Total & 88 & 59 & 147 \\
Days 30 to 34 after insemination & 372 & 17 & 389 \\
Blood pregnancy test positive & 0 & 329 & 329 \\
Blood pregnancy test negative & 372 & 346 & 718 \\
Total & & & 80 \\
35 d after insemination & 64 & 50 & 50 \\
Blood pregnancy test positive & 0 & 66 & 130 \\
Blood pregnancy test negative & 64 & & \\
Total & & 50 & \\
\hline
\end{tabular}

of the bovine PAG-1 ELISA for serum was greater than $95 \%$ on d 36 after AI. Furthermore, bovine PAG-1 could be detected in milk after d 150 of pregnancy. The thrust of the current research efforts is to develop PAG tests that are more sensitive so that pregnancy can be diagnosed sooner after AI. Silva et al. (2007) tested the accuracy of a PAG ELISA on d 27 after AI in a field trial. Their study yielded results comparable with those described herein for a rapid ELISA blood test. The similarity of the results was not surprising, because the rapid ELISA test (this report) and the PAG ELISA (Silva et al., 2007) were both adapted from the methods and antibodies described by Green et al. (2005).

Pregnancy diagnosis by using ELISA for PSPB (Sasser et al., 1986) or PAG (Silva et al., 2007) requires technical laboratory skills and sophisticated instruments. The advantage of the rapid ELISA PAG test is that the test can be performed on the farm or at a nearby facility in approximately $90 \mathrm{~min}$ and requires only a simple thermostatically controlled water bath.
The diagnosis of pregnant or nonpregnant can be made by a subjective visual assessment of blue color with a high degree of accuracy. Because of the relatively short half-life of the PAG detected by the assay (Green et al., 2005), pregnancy detection with the rapid ELISA test was performed as early as $50 \mathrm{~d}$ postpartum. In addition, the rapid ELISA test was highly accurate when used as early as 25 to $29 \mathrm{~d}$ after insemination (Table 4 ).

Pregnancy diagnosis is most commonly performed by transrectal palpation (Romano et al., 2007) or transrectal ultrasonography (Fricke, 2002). Pregnancy detection by palpation is only appropriate for cows that are $\geq 35 \mathrm{~d}$ after AI. The accuracy of palpation depends on the skill of the practitioner and the stage of pregnancy. Ultrasonography can be used to detect pregnancy sooner after AI and has achieved acceptable accuracy by d 26 and 29 after AI in dairy heifers and cows, respectively (Romano et al., 2006). Silva et al. (2007) concluded that transrectal ultrasonography on d 27 after AI increased the proportion of false posi-

Table 4. Sensitivity, specificity, positive predictive value (PPV), negative predictive value (NPV), and accuracy (ACY) ( \pm SE) for the rapid ELISA pregnancy test when used for dairy cows, dairy heifers, beef cows, and beef heifers on different days after insemination ${ }^{1}$

\begin{tabular}{|c|c|c|c|c|c|}
\hline $\begin{array}{l}\text { Days after } \\
\text { insemination }\end{array}$ & Sensitivity, \% (n/n) & Specificity, \% (n/n) & $\mathrm{PPV}, \%(\mathrm{n} / \mathrm{n})$ & $\mathrm{NPV}, \%(\mathrm{n} / \mathrm{n})$ & $\mathrm{ACY}, \%(\mathrm{n} / \mathrm{n})$ \\
\hline $\begin{array}{l}25 \text { to } 29 \\
(\mathrm{n}=147) \\
30 \text { to } 34 \\
(\mathrm{n}=718) \\
\geq 35 \\
(\mathrm{n}=130)\end{array}$ & $\begin{array}{c}98.8 \pm 1.1 \\
(87 / 88) \\
100 \\
(372 / 372) \\
100 \\
(64 / 64)\end{array}$ & $\begin{array}{l}91.5 \pm 3.6^{\mathrm{a}} \\
(54 / 59) \\
95.1 \pm 1.2^{\mathrm{a}} \\
(329 / 346) \\
75.8 \pm 5.3^{\mathrm{b}} \\
(50 / 66)\end{array}$ & $\begin{array}{l}94.6 \pm 2.4^{\mathrm{a}} \\
(87 / 92) \\
95.6 \pm 1.1^{\mathrm{a}} \\
(372 / 389) \\
80.0 \pm 4.5^{\mathrm{b}} \\
(64 / 80)\end{array}$ & $\begin{array}{c}98.2 \pm 1.8 \\
(54 / 55) \\
100 \\
(329 / 329) \\
100 \\
(50 / 50)\end{array}$ & $\begin{array}{l}95.9 \pm 1.6^{\mathrm{a}} \\
(141 / 147) \\
97.6 \pm 0.6^{\mathrm{a}} \\
(701 / 718) \\
87.7 \pm 2.9^{\mathrm{b}} \\
(114 / 130)\end{array}$ \\
\hline
\end{tabular}

\footnotetext{
${ }^{\mathrm{a}, \mathrm{b}}$ Mean percentages having different superscript letters differ $(P<0.05)$.

${ }^{1}$ Sensitivity $=($ number of cattle correctly diagnosed with a positive blood pregnancy test/the number of cattle with positive ultrasonographic pregnancy test $) \times 100$; specificity $=$ (number of cattle correctly diagnosed with a negative blood pregnancy test/number of cattle with a negative ultrasonographic pregnancy test $) \times 100 ; \mathrm{PPV}=$ (number of cattle correctly diagnosed with a positive blood pregnancy test and a positive ultrasonographic pregnancy test/total number of cattle with a positive blood pregnancy test) $\times 100$; NPV $=$ (number of cattle correctly diagnosed with a negative blood pregnancy test and a negative ultrasonographic pregnancy test/total number of cattle with a negative blood pregnancy test $) \times 100$; and accuracy $=($ number of correct blood pregnancy tests/total number of blood pregnancy tests $) \times 100$.
} 
tives when compared with ultrasound examinations at a later time when the embryo could be imaged. Two advantages of ultrasonography over the rapid ELISA test are the instantaneous diagnosis of pregnancy and the ability to evaluate uterine and ovarian morphology of nonpregnant animals. Disadvantages of transrectal ultrasonography are the cost of equipment and the technical skill required to perform the procedure (Fricke, 2002). In addition, rectal palpation introduces the possibility of increased embryonic mortality (Franco et al., 1987), and any transrectal procedure may transmit bovine leukemia virus (Kohara et al., 2006).

Results for the rapid ELISA test were generally consistent for dairy and beef cattle and for heifers and cows. We did find a lower PPV in dairy cows than in dairy heifers. This may be due to early embryonic losses that are more common in dairy cows (Santos et al., 2004). Embryonic losses will increase the number of false-positive cows because of residual PAG in the blood (detectable for approximately 1 wk after embryonic death; Szenci et al., 2003). The lower specificity, PPV, and ACY for cows $\geq \mathrm{d} 35$ (Table 4) can be explained in part by 14 cows that were recorded as "rechecks" on the veterinary record and whose blood test results were false positive. These cows were PAG-tested and examined by ultrasonography $1 \mathrm{wk}$ before the final PAG test and did not have a definitive result by ultrasonography. At "recheck" (1 wk later), the cows were diagnosed nonpregnant by ultrasonography but were PAG positive, suggesting that embryonic loss had occurred between the first ambiguous ultrasound examination and the second definitive (not pregnant) ultrasound examination.

The rapid ELISA pregnancy test was highly accurate for detecting pregnancy in dairy and beef cattle. Sensitivity and NPV were nearly $100 \%$ in all cases and this result implies a minimal risk of misdiagnosing a pregnant cow as nonpregnant. The accuracy of the test was comparable to other common methods of pregnancy detection such as rectal palpation, transrectal ultrasonography, and PSPB detection. This rapid ELISA PAG-based test can be a valuable tool for pregnancy detection. Our results indicate the test is highly accurate $25 \mathrm{~d}$ after AI. These features provide the herd veterinarian or producer with a new, safe, and efficient tool for reproductive management.

\section{ACKNOWLEDGMENTS}

The authors thank A. Brauch and D. Wilson (Division of Animal Sciences, University of Missouri), the staff of the University of Missouri Foremost Farm (dairy), and the University of Missouri South Farm (beef) for the assistance during the completion of this work. We would like to thank Hombstead Farm for the use of cattle from their beef farm.

\section{REFERENCES}

El-Zarkouny, S. Z., J. A. Cartmill, B. A. Hensley, and J. S. Stevenson 2004. Pregnancy in dairy cows after synchronized ovulation regimens with or without presynchronization and progesterone. J. Dairy Sci. 87:1024-1037.

Franco, O. J., M. Drost, M. J. Thatcher, V. M. Shille, and W. W. Thatcher. 1987. Fetal survival in the cow after pregnancy diagnosis by palpation per rectum. Theriogenology 4:631-644.

Fricke, P. M. 2002. Scanning the future-Ultrasonography as a reproductive management tool for dairy cattle. J. Dairy Sci. 85:1918-1926.

Friedrich, M., and W. Holtz. 2009. Establishment of an ELISA for measuring bovine pregnancy-associated glycoprotein in serum or milk and its application for early pregnancy detection. Reprod. Domest. Anim. In press.

Gábor, G.. F. Tóth, L. Ozsvári, Z. Abonyi-Tóth, and R. G. Sasser. 2007. Early detection of pregnancy and embryonic loss in dairy cattle by ELISA tests. Reprod. Domest. Anim. 42:633-636.

Green, J. A., T. E. Parks, M. P. Avalle, B. P. Telegu, A. L. McLain, A. J. Peterson, W. McMillan, N. Mathialagan, R. R. Hook, S. Xie, and R. M. Roberts. 2005. The establishment of an ELISA for the detection of pregnancy-associated glycoproteins (PAGs) in the serum of pregnant cows and heifers. Theriogenology 63:14811503.

Kohara, J., S. Konnai, and M. Onuma. 2006. Experimental transmission of bovine leukemia virus in cattle via rectal palpation. Jpn. J. Vet. Res. 54:25-30.

Moreira, F., C. Orlandi, C. A. Risco, R. Mattos, F. Lopes, and W. W. Thatcher. 2001. Effects of presynchronization and bovine somatotropin on pregnancy rates to a timed artificial insemination protocol in lactating dairy cows. J. Dairy Sci. 84:1646-1659.

Romano, J. E., J. A. Thompson, D. W. Forrest, M. E. Westhusin, M. A Tomaszweski, and D. C. Kraemer. 2006. Early pregnancy diagnosis by transrectal ultrasonography in dairy cattle. Theriogenology $66: 1034-1041$

Romano, J. E., J. A. Thompson, D. C. Kraemer, M. E. Westhusin, D. W. Forrest, and M. A. Tomaszweski. 2007. Early pregnancy diagnosis by palpation per rectum: Influence on embryo/fetal viability in dairy cattle. Theriogenology 67:486-493.

Santos, J. E. P., W. W. Thatcher, R. C. Chebel, R. L. A. Cerri, and K. N. Galvão. 2004. The effect of embryonic death rates in cattle on efficacy of estrus synchronization programs. Anim. Reprod. Sci. $82-83: 513-535$.

Sasser, R. G., and C. A. Ruder. 1987. Detection of early pregnancy in domestic ruminants. J. Reprod. Fertil. Suppl. 34:261-271.

Sasser, R. G., C. A. Ruder, K. A. Ivani, J. E. Butler, and W. C. Hamilton. 1986. Detection of pregnancy by radioimmunoassay of a novel pregnancy-specific protein in serum of cows and a profile of serum concentrations during gestation. Biol. Reprod. 35:936942.

Silva, E., R. A. Sterry, D. Kolb, N. Mathialagan, M. F. McGrath, J. M. Ballam, and P. M. Fricke. 2007. Accuracy of a pregnancyassociated glycoprotein ELISA to determine pregnancy status of lactating dairy cows twenty-seven days after timed artificial insemination. J. Dairy Sci. 90:4612-4622.

Snedecor, G. W., and W. G. Cochran. 1989. Statistical Methods. 8th ed. Iowa State University Press, Ames.

Szenci, O., J. F. Beckers, J. Sulon, M. M. Bevers, L. Börzsönyi, L. Fodor, F. Kovács, and M. A. Taverne. 2003. Effect of induction of late embryonic mortality on plasma profiles of pregnancy associated glycoprotein 1 in heifers. Vet. J. 165:307-313. 